\title{
The Implementation of Free Software in Firms: an Empirical Analysis
}

Carmen de Pablos Heredero. Rey Juan Carlos University. Spain carmen.depablos@urjc.es

David López Berzosa. University of Leon. Spain david.lopez@urjc.es

Roberto Santos Santos. Telefónica. Spain roberto.santossantos@gmail.com

\begin{abstract}
This article presents the findings of a research aimed at characterizing open source migration initiatives. Thirty experiences have been considered in total, ninety of them are Public Administrations and the rest are private firms, operating different industries in eight different countries. Open source migration projects have become a recent research topic, especially from the managerial perspective. To overcome the lack of theoretical models, an empirical approach relying on grounded theory has been adopted. This inductive approach allows theory building and hypothesis formulation. According to the results, migrating from proprietary into open source is dependent on contextual and organizational factors, as for example, the need of the change itself, the political support for the change, the access to IT resources, the organizational climate, the motivation of the human resources, and the leadership style for the project or the firm complexity. Besides, migration efforts imply strategic and organizational consequences that the organization must properly evaluate beforehand.
\end{abstract}

Keywords: open source software, organizational change, grounded theory

\section{INTRODUCTION}

The paradigm of free, open source (F/OSS) as a radical approach to software development started in the early seventies. In the nineties it has been consolidated as an alternative business model. Since then F/OSS has been thoroughly studied from a technical perspective (Raymond, 1999; Hunter, 2006; Rossi, 2006 and Berry, 2008) and as an emerging economic market (Lerner and Tirole, 2002; Lerner and Tirole, 2005 and Riehle, 2007). Free software can be defined as a group of programs developed and 
distributed to offer the final users the freedom to execute copy, distribute, study, change and improve them according to their own needs.

The free software paradigm is not a new one. It appears in the seventies as a natural consequence of creating and being creative with new software applications. In the nineties the free software movement finds a key element: the operating system, Linux, as the most important example of a product of success in this area. Internet promotes the model of co-operation proposed by the free software movement. Open standards as for example, xbrl, provide new interoperability possibilities for Public Administrations and Private Firms (Bonson, et al. 2009). Today, free software is a quite established concept that can offer new and more efficient business models for the information systems at firms.

F/OSS is arguably a cost-effective solution especially in the public sector and in contexts involving large hardware requirements such as education (Lerner and Tirole, 2002; Riehle, 2007; Lakhan and Jhunjhunwala, 2008). The application of F/OSS tools promotes innovation and industry development worldwide (David and Steinmueller, 1994, Shiff, 2002, Von Hippel and Von Krogh, 2003, Bitzer and Schröeder, 2005, Osterloh and Rota, 2007). F/OSS migration initiatives are quite new in the international context, many of them started at the beginning of the 2000s and many others are still in progress (Ahmed, 2005; UOC, 2009).

Notwithstanding the benefits that F/OSS poses for Administrations and large companies, there is still some reluctance to use it among them. Migrating into F/OSS -and to any other service for that matter- is as Mr. Schieß1, technical leader at Munich city hall claims: "LiMux is not a technical project", he says. Initially, the team approached the migration as a classical IT problem, but the real issues turned out to be different. "It's all about managing change for and with people." At this point we are able to confirm this quote as some of our interviewees do agree with Mr Schießl.

F/OSS offers firms more efficient possibilities in the use of their technological resources. In a recent Report published in April 2009 by the EOI in Spain, different positive effects of F/OSS are stressed (EOI, 2009),

- It constitutes an opportunity for firms and Public Administrations, since it means a global technological option.

- It promotes public participation.

- It optimizes the computing costs. 
- It increases the possibilities of choosing and optimizing software and hard- ware products.

- It offers possibilities for increasing the degree of development in the information society.

A recent study on the use of open source software at Universities and Research Centers (CENATIC, 2009) shows how $60 \%$ of servers at University, $42 \%$ of Data Base Systems, $67 \%$ of Institutional email services, $87 \%$ of tools for managing contents and a $90 \%$ of on line teaching programs are based on free software standards.

The purposes of this paper are twofold. In the first place, we present results regarding international F/OSS migration experiences. In the second place, we try to provide insights into open source adoption by organizations.

The latter goal is paramount to define adequate public policies aimed at fostering F/OSS adoption whereas the former goal provides practitioners with guidelines to maximize value in migration initiatives.

\section{QUALITATIVE INDUCTIVE RESEARCH APPROACH}

According to the above mentioned purposes of this study, a microanalysis approach centered on organizational research is mandatory.

There is abundant literature related to technology adoption processes as far as end users are concerned (Venkatesh et al., 2003; Sameh and Izak, 2009). Existing models are able to identify which factors intervene in any user deciding to embrace a new technology implementation.

Adopting open source and subsequent migration of existing services is not a process conducted by a single person not even by a single business unit.

Research in open source as an alternative approach to software development and licensing has been conducted mostly following quantitative methods. They rely on large data sets; provide useful results valid in technical areas concerning to software engineering such as quality assurance or new practices to develop software.

Grounded theory belongs to the set of qualitative research methods aimed at developing theory grounded in existing data gathered from real scenarios (Myers, 2009). Being grounded theory an inductive, discovery methodology it allows to produce emergent theory in areas in which there is still knowledge gaps.

Grounded theory is specially suited in context-based, process-oriented descriptions of 
organizational phenomena (Myers, 1997). Although it was firstly applied in psychology (Glaser and Strauss, 1967; Strauss and Corbin, 1990) it has afterwards been successfully extended to the information systems area (Orlikwoski, 1991, 1993, Garvin, 1998); including open source research (Dedrick and West, 2005).

Therefore the present approach departs from existing quantitative, positivistic approaches (Gonzalez-Barahona, 1991, 2004; Wheeler, 2007) in two aspects: First it provides a micro-level, that is to say, a firm centered, perspective to open source adoption. Second, it provides inductive methods to build theory and provide results. No previous hypotheses are formulated with regards to F/OSS adoption; on the contrary theory is being developed incrementally according to revealed data. We believe the present approach complements the existing literature (Coleman and O'Connor 2007, 2008) in providing a broader F/OSS perspective.

\subsection{RESEARCH METHOD}

Qualitative research based on grounded theory is conducted in four main stages: data collection, open coding, axial (or selective) coding and finally the theoretical part (Glaser and Strauss, 1967; Myers, 2009).

Once that the data have been collected and transcribed, the open coding process analyses the text (either sentences or paragraphs) summarizing it by using descriptive codes representing observed phenomena. These codes will evolve into categories as they emerge from the data. To do so, it is important to perform a constant comparison in search for similarities and differences or recurring patterns as the analysis progresses.

In the second stage, termed either axial or selective (depending on which version of grounded theory is being used), the main objective is to further refine the concepts previously identified along existing interactions between those concepts.

Finally theoretical coding establishes explicit causal or correlation linkages between the concepts, hence formulating a theory sustained in observed facts.

\section{Data collection}

In total 30 migration projects have been collected (Tables 1 I and II). Following the Glaser and Strauss' technique of theoretical sampling, the migration projects have been selected according to maximum variability in terms of context, size, purpose, ICT intensity among others. Having several factors intervening at different intensity levels is key to define concepts, categories and relationships, as for example in emergent theory 
(Strauss and Corbin, 1990).

Theoretical sampling is cumulative in the sense that future migration experiences add value to existing knowledge by suggesting new concepts to be considered for successful F/OSS migration initiatives. We posit that adopting an evolutionary approach to theory building alleviates the obsolescence that technical migration guides may have whenever disruptive technologies or standards emerge.

Nineteen of the total documented experiences correspond to public administrations from eight different countries (Brazil, Finland, France, Germany, Rumania, Spain, UK, USA) and ten for-profit organizations from small medium companies to large multinationals. For every organization the following aspects have been initially considered:

\section{Migration objectives}

2. Migration timeframe

3. Type of software or service migrated

4. Migration cost

5. Migration critical success factors

6. Migration critical failure factors

7. Migration outcome

8. Perceived benefits

The data collection process in grounded theory is conducted iteratively (Glaser and Strauss, 1967) starting with a general exploratory analysis that will afterwards be completed with more focused approaches towards relevant topics and structured interviews. Please refer to the following table for a concise description of the firms considered along the research.

\section{Data Analysis}

Inductive analysis tries to find relevant concepts and relationships among them. Initially in the open coding process, researchers thoroughly analyze existing data and summarize it into categories (Strauss and Corbin, 1990). In a second stage, axial coding, initial categories are further developed into subcategories representing variations along dimensions (i.e. axial coding), these subcategories often match questions such as: when, how, why, where and what for. 


\begin{tabular}{|c|c|c|}
\hline \multicolumn{3}{|l|}{ Public Administrations } \\
\hline & Size & Purpose \\
\hline Case1. Munich City Hall & Large & Desktop operating system and applications \\
\hline Case2. Estepona City Hall & Small & Desktop operating system and applications \\
\hline Case3. French pólice & Large & Desktop operating system and applications \\
\hline Case 4. USA postal service & Large & Backoffice, ERP \\
\hline Case 5. Birmingham City Hall & Medium & Desktop operating system and applications \\
\hline Case 6. Zaragoza City Hall & Medium & Desktop operating system, applications and Backoffice \\
\hline Case 7. Regional administration of Valencia & Large & Desktop operating system, applications and Backoffice \\
\hline Case 8. Meteo. Service of Bucarest & Small & New software development \\
\hline Case 9. Ministry of Justice of Finland & Large & Desktop operating system and applications \\
\hline Case 10. Healthcare agency of Castilla la Mancha & Large & Desktop operating system and applications \\
\hline Case 11. Amorebieta-Etxano City Hall & Small & Desktop operating system and applications \\
\hline Case 12. Toledo City Hall. & Small & Desktop operating system and applications \\
\hline Case 13. Transportation agency of Valencia & Medium & Desktop operating system and applications \\
\hline Case 14. University of Murcia & Medium & Desktop operating system and applications \\
\hline Case 15. Bartol. Grau City Hall & Small & Desktop operating system and applications \\
\hline Case 16. Ministry of Education of Brasil & Large & Desktop operating system and applications \\
\hline Case 17. Metro Sao Paulo & Medium & New software development \\
\hline Case 18. Brasil Goverment & Large & Desktop operating system and applications \\
\hline Case 19. Arles City Hall & Small & New software development \\
\hline
\end{tabular}

Table 1. The firms in the research (I)

Given the intra-firm analysis, perspective adopted in this research, F/OSS migration experiences are considered internal processes of change. We believe this process-centered approach reflects real organizations' structures facilitating its adoption in existing business units.

Figure 1 reveals main categories and subsequent subcategories emerging from the analysis. Main categories: Adoption process, Migration Process and Migration Results correspond to the lifecycle stages of most part of the software projects, we posit this is due to established practices in companies. Then, for each main category there exists several subcategories such as ICT intensity, interoperability, the existing user's database 
and external impacts, amongst others. These subcategories represent factors intervening in the global process of open source adoption.

\begin{tabular}{|c|c|c|}
\hline \multicolumn{3}{|l|}{ Multinationals } \\
\hline & Size & Purpose \\
\hline Case 20. Oshkosh Defense & Large & Specific software development (Real time) \\
\hline Case 21. PSA Peugeot Citröen & Large & Desktop operating system, applications and Backoffice \\
\hline Case 221. Volvo Car Corporation & Large & Desktop operating system, applications and Backoffice \\
\hline Case 23. Audi & Large & Specific software development (Supercomputing and Simulation) \\
\hline \multicolumn{3}{|l|}{ SME's } \\
\hline & Size & Purpose \\
\hline Case 24. Mipesa & Small & Desktop operating system and applications \\
\hline Case 25. Tool Machining industries. & Medium & Desktop operating system and applications \\
\hline Case 26. Alimarket & Medium & Desktop operating system and applications \\
\hline Case 27. Caja Guadalajara & Small & Desktop operating system, applications, ERP, CRM, Backoffice \\
\hline Case 28. Soc. ARQVIPO & Small & Desktop operating system, applications and Backoffice \\
\hline Case 29. ARSYS & Medium & Desktop operating system, applications and Backoffice \\
\hline Case 30. Rentalia & Medium & New software development \\
\hline
\end{tabular}

Table 1. The firms in the research (II)

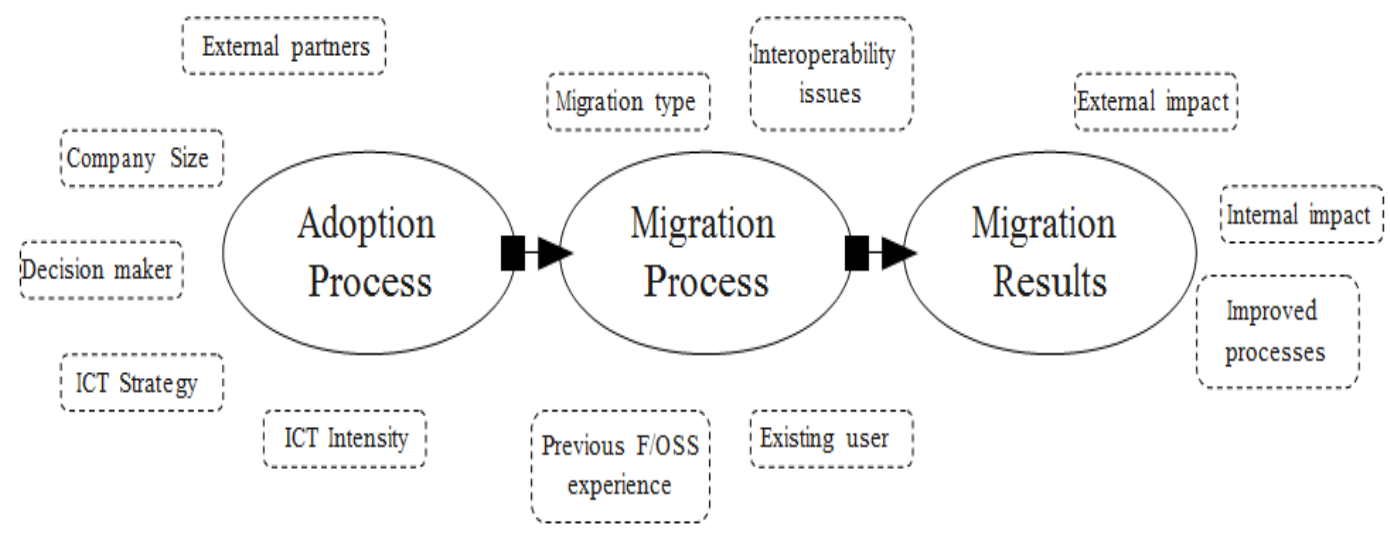

Figure 1. F/OOS migration lifecycle 


\subsection{RESEARCH RESULTS}

Three main modes of F/OSS adoption emerge from the analysis: (1) Organizations that look for vendor independence. They consider open source software as a strategic asset. (2) Organizations embracing open source as a better option than private one in terms of performance or new features. (3) Finally, in the third adoption mode, organizations striving for budget constrain. They consider open source as a cost-effective option in terms of licensing and hardware obsolesce.

\section{Group A. Strategic movers}

In this adoption mode, organizations have faced vendor issues such as forced migrations, ceasing product support or spiraling ICT costs. Removing vendor lock-ins is considered a priority by top executives who define strategic plans to evolve into the F/OSS paradigm.

These organizations tend to be large both in human resources and ICT budget. They have specific staff dedicated to ICT development and support. They are mostly Public Administrations or large private firms.

Being intensive users of ICT services, for instance Public Administrations, they face interoperability issues with existing services as well as users' resistance to change established routines and procedures. They adopt a gradual approach to software migration demanding fixed timetables to be completed. Sometimes rescheduling is mandatory.

Migration processes in this case often require of external partners with technical expertise and large scale deployment experience, especially if the organization lacks of previous experience or faces challenging scenarios of non-interoperable technologies and information.

The outcome of migration initiatives in this case is positive in general providing optimist results in terms of improved internal processes (Table 2). Besides they usually create positive externalities in other business units. Due to the large scale nature of these initiatives, they often impact society in general, either by providing new services or offering new and improved software. Clear examples of this adoption mode are: Munich City Hall, French Police or USA Postal Service. 


\begin{tabular}{|c|c|}
\hline \multicolumn{2}{|l|}{ Group A. Strategic movers } \\
\hline \multicolumn{2}{|l|}{ Adoption Process } \\
\hline Company size & Usually large \\
\hline Decision makers & Mostly from the top, chief executive level \\
\hline ICT strategy & Vendor independence, flexibility to specific requirements \\
\hline Staff expertise & Mostly large, existing ICT units \\
\hline ICT intensity & High, large base of hardware and software \\
\hline External partners. Feasibility & Usually yes, depending on internal expertise \\
\hline Previous analysis & Yes, cost analysis, technical analysis \\
\hline \multicolumn{2}{|l|}{ Migration Process } \\
\hline Migration type & Structural or core services \\
\hline Previous F/OSS experience & No necessarily \\
\hline External partners. Implementation & Most of the times \\
\hline Interoperability barriers & Usually large due to existing applications \\
\hline Change management & Emphasis on educational programs, gradual approach \\
\hline Process reengineering & Usually large specially when existing procedures \\
\hline Existing users base & Large \\
\hline Migration timeframe & Years \\
\hline \multicolumn{2}{|l|}{ Migration Results } \\
\hline Further intentions to migrate & Usually adopting a non-stop rolling over approach \\
\hline Impact on another units & Most of the times \\
\hline Impact on external organizations & Frequent \\
\hline Goal achievement & Frequent, sometimes rescheduling is necessary \\
\hline Improved processes & Most of the times \\
\hline
\end{tabular}

Table 2. Group A results

\section{Group B. Feature seekers}

This category is mainly composed by medium to large organizations with intensive use of ICT in their business processes looking for new opportunities to improve current existing IT capabilities, for instance supercomputing or embedded systems. They are mostly private firms. Examples of this mode are Audi, Peugeot and Caja Guadalajara.

Migration projects are initiated by internal experts taking advantage of recent developments, either software or hardware. One IT expert working for a financial institution claims that: "We are not fans of F/OSS we stick to the best solution given the context and existing options". 
In spite of having technical expertise, they usually collaborate with external partners for specific expertise.

Due to the non-core nature of the affected services, interoperability is not a concern, neither are end users who remain waiting to be included in the reengineering programs (Table 3).

\begin{tabular}{|c|c|}
\hline Group B. Feature seekers & \\
\hline \multicolumn{2}{|l|}{ Adoption Process } \\
\hline Company size & Medium to Large \\
\hline Decision makers & Mostly internal staff at technical units \\
\hline ICT strategy & Oriented to business support or new features \\
\hline Staff expertise & Usually large, existing ICT units \\
\hline ICT intensity & High, large base of hardware and software \\
\hline External partners. Feasibility & Seldom \\
\hline Previous analysis & Seldom \\
\hline \multicolumn{2}{|l|}{ Migration Process } \\
\hline Migration type & Non-core services \\
\hline Previous F/OSS experience & No necessarily \\
\hline External partners. Implementation & Most of the times \\
\hline Interoperability barriers & Non relevant except in legacy applications \\
\hline Change management & Procedures to ensure minimum impact on operations \\
\hline Process reengineering & Minimum \\
\hline Existing users base & Minimum \\
\hline Migration timeframe & Months \\
\hline \multicolumn{2}{|l|}{ Migration Results } \\
\hline Further intentions to migrate & Yes, as long as required \\
\hline Impact on another units & Minimum \\
\hline Impact on external organizations & Usually \\
\hline Goal achievement & Yes \\
\hline Improved processes & Yes, improved or extended features \\
\hline
\end{tabular}

Table 3. Group B results

\section{Group C. Budget optimizers}

Small and medium companies often adopt open source as the best option in terms of the price performance ratio. They usually implement new, non-core services, providing open source as an inexpensive approach. 
The typical profile is a local Administration or private SME operating in a nonintensive ICT market, as for example Arles City Hall, Mipesa and Toledo City Hall.

\begin{tabular}{|c|c|}
\hline Group C. Budget optimizers & \\
\hline Adoption Process & \\
\hline Company size & Usually SME \\
\hline Decision makers & Internal staff \\
\hline ICT strategy & Oriented to business activities support, minimizing costs \\
\hline Staff expertise & Medium to small \\
\hline ICT intensity & Medium to small \\
\hline External partners. Feasibility & Seldom \\
\hline Previous analysis & Minimum \\
\hline Migration Process & \\
\hline Migration type & Non-core services \\
\hline Previous F/OSS experience & Medium to minimum \\
\hline External partners. Implementation & Seldom \\
\hline Interoperability barriers & Minimum \\
\hline Change management & Often no required \\
\hline Process reengineering & Often no required \\
\hline Existing users base & Usually Small \\
\hline Migration timeframe & Months \\
\hline Migration Results & \\
\hline Further intentions to migrate & Yes, cost-driven \\
\hline Impact on another units & Seldom \\
\hline Impact on external organizations & Seldom \\
\hline Goal achievement & Yes \\
\hline Improved processes & Yes, new processes \\
\hline
\end{tabular}

Table 4. Group C results

\section{IMPLICATIONS FOR F/OSS MIGRATION PROCESSES}

As a general rule it seems a good practice to look for interoperable technologies in existing or future software deployments. They ensure optimal vendor independence and flexibility to adapt to business requirements (Boixo and Flores, 2005).

Some companies adopt a migration strategy relying on early adopters to test prototypes adapting them according to the received feedback. We consider this approach quite adequate for it ensures business continuity while involving users from start; this reinforces the idea that F/OSS migration initiatives entail technical, organizational and 
business process reengineering (Hammer, 1990).

According to our data, most of the times large organizations hire external companies providing technical expertise or migration experience. Furthermore there exist some cases, mainly in very specialized areas such as mathematical modeling or embedded hardware, in which several partners collaborate to come up with an adequate solution.

No matter the F/OSS adoption mode, strategic, functional or optimizing, companies start considering open source as an alternative to specific issues and gradually have it adopted in subsequent initiatives. This behavior based on reinforced trust is consistent with technology acceptance models if only at an organization level (Vang et al, 2003).

Four broad areas need to be considered along large scale F/OSS migration projects: the existence of managerial support, the existence of clear procedures established to induce business process reengineering, effective project management and wide commitment to involve stakeholders in the implementation process

Strong managerial support (Finney and Corbett, 2007) is an important factor according to the literature review. Besides, in our recent interview with firms migrating to F/OSS in the Spanish market, this aspect is highly stressed as one of the most important critical success factors. Top management support provides leadership and necessary long term commitment. Observed leadership styles, especially in large public administrations, correspond to relevant change management literature (Kotter, 1995).

Clear business process reengineering procedures The existence of clear procedures established for the required reengineering of business processes in the firm has mainly to do with managing the cultural change, identified by Al-Mashari et al., 2003; Fui-Hoon et al., 2003 and Finney and Corbett, 2007.

Migrating to a new system requires the redesign of existing business processes. Many times the new implementations fail because some firms underestimate the extent to which they have to change processes. Organizations should be prepared for fundamental changes (Motwani et al., 2002).

Observed migration processes in large organizations is a matter of years and gradual initiatives, this pattern is congruent with the concept of induced, incremental processes of change (Garvin, 1998).

Effective project management, the project management plans co-ordinate and control the complex and diverse activities of modern, industrial and commercial projects. The 
implementation of a new system implies working on different activities, all involving business functions and requiring a long time perspective (Falkowski et al., 1998; Holland and Light, 1999; Rosario, 2000; Sommers and Nelson, 2003).

According to our observations, migration projects often face complex scenarios combining non interoperable systems and large base of existing users. Interoperability can arguably be one of the limiting factors for F/OSS adoption.

Wide involvement along the firm refers to the existence of a communication plan (Falkowski et al., 1998; Holland and Light, 1999; Rosario, 2000; Mabert, 2003). Whenever F/OSS migration attempts to integrate information across all the areas in an organization, it is important to get the needed support from all functional areas. Everyone in the organization must be responsible for the whole system and key users from different departments must be informed of the project implementation phases.

When realizing the implementation of the new system, a previous methodology must be established. The steps in the project and the involvement of each of the key-users and the consultancy team that takes part in the implementation must be clearly specified.

The existence of reliable vendor support and external services is close referred to the selection of the tools (Sommers and Nelson, 2003, Al-Mashari et al., 2003) and the consultant selection and relationship.

It is very important for the customer that decides to migrate to a new system in his/her organization and for the providers, to align the implementation services with the achieving of the objectives for the project. Those objectives must be defined in the design document elaborated once that the analysis and requirements feeding phases have been finished. The design document must contain the situation of the business processes before the implementation and the future situation, once that the business process reengineering effort to implement the new software, or service, has taken place.

\section{FUTURE WORK}

The results of the present research confirm a series of perceptions such as that F/OSS is a real alternative to proprietary software, scales up in large organizations, reduces vendor independence, optimizes existing hardware, requires detailed project analysis and project management.

F/OSS adoption offers good opportunities for reaching efficiency, flexibility and security in organizational processes, but it also poses challenging questions. Modeling users' response to technology changes is paramount to integrate new software into 
already existing organizations. At this point, recent results enhance former Technology Acceptance Models (TAM) by considering software as a social actor within the organization able to interact with employees at increasing sophistication levels (Sameh and Izak, 2009). We believe that further research could provide interesting results complementing this interaction-centric model with constructs valid at a firm and intra firm level (Pinsker, 2008). We find of interest to promote future research in the application of financial and accounting methodologies that allow us finding quantitative measures based on the investment that firms perform on free open source solutions and the financial results achieved based on the accounting figures. Following previous interesting research in other technologies (Escobar et al., 2004), we are now working on some tools that take into account the implementation and development of open source software, operational costs, such as energy, the maintaining of computers, and the management of the system and try to quantify benefits too, as for example the calculation of the return on assets of technological investments.

In every migration project there is always an internal sponsor or a group of people leading the initiative. Further research into leadership aspects of open source projects may serve practitioners to identify best organizational patterns to induce F/OSS adoption.

An interesting fact that emerged during the present research is that some organizations, mainly large multinationals, are able to generate positive externalities in other units or even contribute with their own developments back to the open source community. Being public administrations large ICT consumers providing further insight into effective means to induce innovation, software reutilization for instance, would be an interesting research topic.

We have found that F/OSS does not necessarily imply dramatic budget savings, it rather depends on the specifics of the organization moreover the rate of expected savings depend on several dimensions -being existing user's base one of them- Providing some results in this sense would add value to the open source community.

There is international consensus on the importance that ICT plays on education and development, 10 percent of broadband penetration increases GDP in developed economies up to 1.2 percent. Being F/OSS capable of provisioning computers at lower costs, there may be incentives by governments to engage in national initiatives to promote digital literacy relying on the F/OSS paradigm. Documenting exemplary initiatives in this matter are encouraged. 


\section{REFERENCES}

AHMED, O. (2005): Migrating from proprietary to Open Source: Learning Content Management Systems, Doctoral Dissertation, Department of Systems and Computer Engineering, Carleton University, Ottawa, Ontario, Canada.

AL-MASHARI, M.; AL-MUDIMIGH, A.; ZAIRI, M. (2003): "Enterprise Resource Planning: a taxonomy of critical factors", European Journal of Operational Research, vol. 146: 352-364. http://dx.doi.org/10.1016/S0377-2217(02)00554-4

BERRY, D.M. (2008): Copy, rip, Burn: the Politics of Copyleft and Open Source, Pluto Press. London.

BITZER, J.; SCHRÖEDER, J.H. (2005): "The impact of entry and competition by Open Source Software on Innovation Activity", Industrial Organization 051201, EconWPA. Electronic working paper archive with free content access in www.economicsnetwork.uk BOIXO, I.; FLORES, F. (2005): "New Technical and Normative Challenges for XBRL: Multidimensionality in the COREP Taxonomy", The International Journal of Digital Accounting Research, vol. 5, n. 9: 79-104. http://dx.doi.org/10.4192/1577-8517-v5_3

BONSON, E.; CORTIJO, V., ESCOBAR, T. (2009): “A Delphi Investigation to Explain the Voluntary Adoption of XBRL", The International Journal of Digital Accounting Research, vol. 9: 193-205. http://dx.doi.org/10.4192/1577-8517-v9 7

CENATIC (2009): Study on the situation of Open Source Software in Universities and $R+D$ Centers, Report, Almendralejo.

COLEMAN, G.; O'CONNOR, R. (2008): “Investigating software process in practice: A grounded theory perspective". Journal of Systems and Software, vol. 81, n. 5: 772-784. http://dx.doi.org/10.1016/j.jss.2007.07.027

COLEMAN, G.; O'CONNOR, R. (2007): “Using grounded theory to understand software process improvement: a study of Irish software product companies", Information and Software Technology, vol. 49, n. 6: 742-758. http://dx.doi.org/10.1016/j.infsof.2007.0 $\underline{2.011}$

DAVID, P. STEINMUELLER, E. (1994): "Information Economics and Policy". Special Issue on The Economics of Standards, vol. 6, n. 3-4: 33-45

DEDRICK, J.; WEST, J. (2005): "Why firms adopt Open Source Platforms: A grounded Theory of Innovation and Standards Adoption", MIS Quarterly, Special Issue on Standard 
Making: 33-46.

EOI (2009): The opportunities of free software: capacities, rights and innovation, Internal Report, Escuela de Organización Industrial, Madrid.

ESCOBAR, B.; CULLEN, J.; GONZALEZ, J.M. (2004): "Impacts of the implementation of ERP Systems on Cash Management: the redesign of treaseury processes", The International Journal of Digital Accounting Research, vol. 8, n. 4: 81-96. http://dx.doi.or $\mathrm{g} / 10.4192 / 1577-8517-\mathrm{v} 4 \_2$

FALKOWSKI, G.; PEDIGO, P.; SMITH, B.; SWAMSON, D. (1998): “A recipe for ERP success. Beyond Computing", International Journal of Human-Computer Interaction, vol.16, n. 1: 5-22.

FINNEY, S.; CORBETT, M. (2007): "ERP implementation: a compilation and analysis of critical success factors, Business Process”, Management Journal, vol. 13, n. 3: 329-347.

FUI-HOON, F.; ZUCKWEILER, K.M.; LEE-SHANG, J. (2003): "ERP implementation: Chief Information Officers' Perceptions on Critical Success Factors”, International Journal of Human Computer Interaction, vol.16, n. 1: 5-22. http://dx.doi.org/10.1207/S15 327590IJHC1601_2

GARVIN, D. (1998): "The processes of Organization and Management", Sloan Management Review, vol. 3, n. 2: 24-37.

GLASER, B.G.; STRAUSS, A.L. (1967): The discovery of Grounded Theory: Strategies for Qualitative Research. Aldine Publishing Company. New York.

GONZALEZ-BARAHONA, J. (1991): "Counting Potatoes: the size of Debian 2.2", The European Online Magazine for the IT Professional, vol. 2, n. 6: 22-43.

GONZALEZ-BARAHONA, J. (2004): About free software. Rey Juan Carlos UniversityDykinson. Madrid.

HAMMER, M. (1990): "Reengineering Work: Do not Automate, Obliterate", Harvard Business Review, Autumn: 34-47.

HOLLAND, C.P.; LIGHT, B. (1999): A critical success factor model for ERP implementation", IEEE Software, May/June: 30-36. http://dx.doi.org/10.1109/52.765784

HUNTER, I. (2006): Open Source Data Base Driven Web Development. Chandos. Oxford. 
KOTTER, J. (1995): "Leading change: Why transformation Effort Fail", Harvard Business Review, vol. 23, n. 2: 45-58.

LAKHAN, S.; JHUNJHUNWALA, K. (2008): "Open Source in Education”, Educause Quarterly, vol. 31, n. 2: 32-40.

LERNER, J.; TIROLE. J. (2002): “The simple economics of Open Source", Journal of Industrial Economics, vol. 50, n. 2: 197-234. http://dx.doi.org/10.1111/1467-6451.00174

LERNER, J.; TIROLE, J. (2005): “The Economics of Technology Sharing: Open Source and Beyond", Journal of Economic Perspectives, vol. 19, n. 2: 99-120. http://dx.doi.org/10.1257/0895330054048678

MABERT, V. (2003): "Enterprise Resource Planning: managing implementation process", European Journal of Operational Research, vol. 146, n. 2: 302-314. http://dx.doi.org/10.1 016/S0377-2217(02)00551-9

MOTWANI, J.; MIRCHANDANI, M.; GUNASEKARAN, A. (2002): "Successful implementation of ERP Projects: evidence from two case studies", International Journal of Production Economics, vol. 75: 83-96. http://dx.doi.org/10.1016/S0925-5273(01)00183-9

MYERS (2009): Qualitative Research in Business and Management. Sage. London.

MYERS (1997): "Qualitative Research in Information Systems", MIS Quarterly, vol. 21, n. 2: 241-252. http://dx.doi.org/10.2307/249422

ORLIKOWSKI, W. (1991): "Information Technology and the Structuring of Organizations Research Approaches and Assumptions", Information Systems Research, vol. 2, n. 1: 234-256. http://dx.doi.org/10.1287/isre.2.1.1

ORLIKOWSKI, W. (1993): "CASE Tools as Organizational Change: Investigating Incremental and Radical Changes in Systems Development”, MIS Quarterly, vol. 34, n. 2: 41-54.

OSTERLOH, M.; ROTA, S. (2007): “Open source software development, just another case of collective invention", Research Policy, vol. 36, n. 2: 157-171. http://dx.doi.org/10.1016/j.respol.2006.10.004

PINSKER, R.E. (2008): “An empirical examination of competing theories to explain continuous disclosure technology adoption intentions using XBRL as the example technology", The International Journal of Digital Accounting Research, vol. 8, n. 4: 8196. http://dx.doi.org/10.4192/1577-8517-v8 4 
RAYMOND, C. (1999): "The Cathedral and the bazaar. Knowledge", Technology and Policy, vol. 12, n. 3: 123-135.

RIEHLE, D. (2007): "The Economic Motivation of Open Source: Stakeholder Perspectives", IEEE Computer, vol. 40, n. 4: 27-34.

ROSARIO, J.G. (2000): "On the leading edge: critical success factors in ERP implementation projects", Business World, May: 21-27.

ROSSI, M.A. (2006): "Decoding the green/open source software puzzle: A survey of theoretical and empirical contributions", The Economics of Open Source Software Development, vol. 32 n. 4: 15-55. http://dx.doi.org/10.1016/B978-044452769-1/50002-0

SAMEH, B; IZAK, J. (2009): “The Adoption and Use of IT Artifacts: A New InteractionCentric Model for the Study of User-Artifact Relationships", Journal of the Association for Information Systems, vol. 10, n. 9: 123-147.

SHIFF, A. (2002): "The Economics of Open Source Software: a survey of the early literature", Review of Network Economics, vol. 1, n. 1: 66-74

SOMMERS, G.; NELSON, C. (2003): "A taxonomy of players and activities across the ERP project life cycle", Information and Management, vol. 41, n. 3: 257-278. http://dx.doi.org/10.1016/S0378-7206(03)00023-5

STRAUSS, A.L.; CORBIN, J.M. (1990): Basics of Qualitative Research: Grounded theory, Procedures and Techniques. Sage. London.

UOC (2009): The use of open source in Public Administrations in Spain, Internal Report, Universitat Oberta de Calalunya, Barcelona.

VON HIPPEL, B.; VON KROGH, G. (2003): "Open source software and the privatecollective innovation model: Issues for organization science", Organization Science, vol.14, n. 2: 208-223.

VANG, Y.J.; WANG, Y.M.; LIN, H.H.; TANG, T.I. (2003): "User acceptance of information technology: Toward a unified view”, MIS Quarterly, vol. 27, n. 3: 46-63.

VENKATESH, V.; MORRIS, M.G.; DAVIS, G.; DAVIS, F. (2003): “User acceptance of Information Technology: toward a unified view”, MIS Quarterly, vol. 27, n. 3: 425-478.

WHEELER, D. (2007): Why Open Source Software. Look at the Numbers. Free Press. Boston. 